\title{
Absolute Change in High Sensitivity Cardiac Troponin I for Three Hours is Useful for Diagnosing Acute Myocardial Infarction in the Emergency Department: How to Get to Best Benefit From HS-Troponins in Clinical Practice?
}

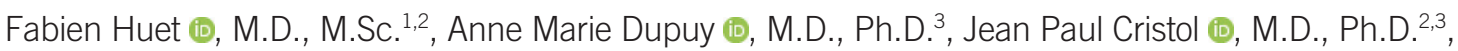 \\ and François Roubille (D), M.D., Ph.D., ${ }^{1,2}$ \\ ${ }^{1}$ Cardiology Department, University of Montpellier, INSERM U1046, CNRS UMR 9214, Montpellier, France; ${ }^{2}$ PhyMedExp, Department of Biochemistry, \\ University of Montpellier, INSERM U1046, CNRS UMR 9214, Montpellier, France; 3Department of Biochemistry, University Hospital of Montpellier, \\ Montpellier, France
}

\section{Dear Editor,}

The latest generation of troponin assays, the high-sensitivity (hs)cardiac troponins (hs-cTn), provide a powerful tool for the diagnosis and management of patients with suspected acute myocardial infarction (AMI). However, these assays are a doubleedged sword, as although they are very sensitive, their results can sometimes be misleading. For instance, hs-cTn do not follow the classical decrease exhibited by other traditional biomarkers such as creatine kinase or non-hs-cTn markers [1]. Thus, physicians should be aware of these characteristics to avoid misinterpretation. In addition, for clinical research purposes, although the management and interpretation of hs-cTn are sometimes tricky, they can also provide unexpected assessments such as an approximation of microvascular occlusion [2,3]. In other words, hs-cTn constitutes a powerful tool that should be used extensively but cautiously.

In a paper by Kim, et al. [4] entitled "Absolute change in high sensitivity cardiac troponin I for 3 hours is useful for diagnosing $A M I$ in the emergency department (ED)", the authors proposed a smart use of hs-cTn value; briefly, they emphasize that using the absolute change of the cardiac hs-cTnl value to diagnose $\mathrm{AMI}$ in the ED is better than using the relative change, expressed as \% of baseline. Although this finding is not completely novel [5, 6], it warrants further exploration.

First, some limitations need to be updated, especially the lack of applicability for other biomarkers including other subtypes of hs-cTn. In addition, the results should be considered with caution, as they were obtained from a single center, with a relatively small population.

The current guidelines recommend the use of relative rather than absolute changes in hs-cTn value to define a recognized pattern of change (changes from 20-60\%) [7]. Importantly, absolute changes of hs-cTn values are not recommended because they are assay dependent; the cut-offs are specifically defined
Received: April 13, 2020

Revision received: April 13, 2020

Accepted: May 19, 2020

Corresponding author: François Roubille, MD, PhD.

Cardiology Department, Montpellier University Hospital, Montpellier University, 371, Avenue du Doyen Gaston Giraud, 34295 Montpellier Cedex 05, France

Tel: +33 7880141 36, E-mail: francois.roubille@gmail.com

\section{(c) (1) (9)}

\section{(C) Korean Society for Laboratory Medicine}

This is an Open Access article distributed under the terms of the Creative Commons Attribution Non-Commercial License (https://creativecommons.org/licenses/by-nc/4.0) which permits unrestricted non-commercial use, distribution, and reproduction in any medium, provided the original work is properly cited. 
for each assay, based on the 0-1 hour kinetics, and the use of this strategy should be restricted to a very short list of manufacturers. Thus, this study provides important data, not only by emphasizing the importance of the absolute change in hs-cTnl values, but also by suggesting a standard delay of three hours between assays.

These results could be of interest, especially during very early admission to the ED or for specific subpopulations but need to be further explored. For instance, could this absolute elevation be more relevant in elderly patients or patients with chronic kidney disease, known to have high baseline troponins, clearly associated with long-term mortality [8]?

Importantly, the negative predictive value (NPV) appears to be good in various studies but decreases significantly when very short delays are considered [9].

Interestingly, some authors have established similar NPVs for hs-cTn I or T using various assays [6], while others have suggested less perfect NPVs (96.5\%) using an hs-cTnT assay or more importantly when the delay is very short ( $<1$ hour) [10]. Indeed, from a clinical standpoint, a near 100\% NPV is mandatory in order to safely rule out suspected patients.

In conclusion, clinicians should be aware of this specific issue in order to improve patient management, especially in difficult, real-life clinical setting cases.

\section{ACKNOWLEDGEMENTS}

Not applicable.

\section{AUTHOR CONTRIBUTIONS}

FH, AMD, JPC, and FR conceived, drafted, edited, and approved final manuscript and take full responsibility for its content.

\section{CONFLICTS OF INTEREST}

The authors do not declare any conflicts of interest regarding this work.

\section{RESEARCH FUNDING}

None declared.

\section{ORCID}

Fabien Huet

Anne Marie Dupuy

Jean-Paul Cristol

François Roubille

https://orcid.org/0000-0001-5422-0226

https://orcid.org/0000-0001-6538-3944

https://orcid.org/0000-0001-8563-7278

https://orcid.org/0000-0002-5288-9687

\section{REFERENCES}

1. Laugaudin G, Kuster N, Petiton A, Leclercq F, Gervasoni R, Macia JC, et al. Kinetics of high-sensitivity cardiac troponin $T$ and I differ in patients with ST-segment elevation myocardial infarction treated by primary coronary intervention. Eur Heart J Acute Cardiovasc Care 2016;5:354-63.

2. Huet F, Akodad M, Kuster N, Kovacsik H, Leclercq F, Dupuy AM, et al. An hs-TNT second peak associated with high CRP at day 2 appears as potential biomarkers of micro-vascular occlusion on magnetic resonance imaging after reperfused ST-segment elevation myocardial infarction. Cardiology 2018;140:227-36.

3. Schaaf M, Huet F, Akodad M, Gorce-Dupuy AM, Adda J, Macia JC, et al. Which high-sensitivity troponin variable best characterizes infarct size and microvascular obstruction? Arch Cardiovasc Dis 2019;112:33442.

4. Kim JW, Kim H, Yun Y-M, Lee KR, Kim HJ. Absolute change in high sensitivity cardiac troponin I for three hours is useful for diagnosing acute myocardial infarction in the emergency department Ann Lab Med 2020; 40(6).

5. Reichlin T, Irfan A, Twerenbold R, Reiter M, Hochholzer W, Burkhalter H, et al. Utility of absolute and relative changes in cardiac troponin concentrations in the early diagnosis of acute myocardial infarction. Circulation 2011;124:136-45.

6. Irfan A, Reichlin T, Twerenbold R, Meister M, Moehring B, Wildi K, et al. Early diagnosis of myocardial infarction using absolute and relative changes in cardiac troponin concentrations. Am J Med 2013;126:781-8.e2.

7. Roffi M, Patrono C, Collet JP, Mueller C, Valgimigli M, Andreotti F, et al. 2015 ESC Guidelines for the management of acute coronary syndromes in patients presenting without persistent ST-segment elevation: Task Force for the Management of Acute Coronary Syndromes in Patients Presenting without Persistent ST-Segment Elevation of the European Society of Cardiology (ESC). Eur Heart J 2016;37:267-315.

8. Kuster N, Monnier K, Baptista G, Dupuy AM, Badiou S, Bargnoux AS, et al. Estimation of age- and comorbidities-adjusted percentiles of highsensitivity cardiac troponin T levels in the elderly. Clin Chem Lab Med 2015;53:691-8.

9. Yokoyama H, Higuma T, Endo T, Nishizaki F, Hanada K, Yokota T, et al. "30-minute-delta" of high-sensitivity troponin I improves diagnostic performance in acute myocardial infarction. J Cardiol 2018;71:144-8.

10. Mueller C, Twerenbold R, Reichlin T. Early diagnosis of myocardial infarction with sensitive cardiac troponin assays. Clin Chem 2019;65:490-1. 